\title{
The Role of Apparent Diffusion Coefficient Quantification in Differentiating Benign and Malignant Renal Masses by 3 Tesla Magnetic Resonance Imaging
}

\author{
Cemil Göya ${ }^{1}$, Cihad Hamidi ${ }^{1}$, Yaşar Bozkurt², Alpaslan Yavuz ${ }^{3}$, Suzan Kuday ${ }^{4}$, Hatice Gümüş ${ }^{1}$, \\ Gül Türkçü ${ }^{5}$, Salih Hattapoğlu ${ }^{1}$, Aslan Bilici ${ }^{1}$
}

Background: Diffusion-weighted magnetic resonance imaging (DWI) is a widely-accepted diagnostic modality whose efficacy has been investigated by numerous past studies in the differentiation of malignant lesions from benign entities.

Aims: The aim of this study was to evaluate the efficiency of diffusion-weighted magnetic resonance imaging in the characterization of renal lesions.

Study Design: Diagnostic accuracy study.

Methods: A total of 137 patients with renal lesions were included in this study. The median apparent diffusion coefficient (ADC) values as well as the b 800 and b 1600 signal intensities of normal kidneys, solid components of mixed renal masses, and total cystic lesions were evaluated.

Results: There were significant differences between the ADC values of lesions and normal renal parenchyma, and between the ADC values of benign and malignant renal lesions on DWIs at $b$ values of 800 and 1600 $\mathrm{s} / \mathrm{mm}^{2} \quad(\mathrm{p}<0.001$ and $\mathrm{p}<0.001$, respectively). There were significant differences between the ADC values of Bosniak Category 1 and 2 cysts and the ADC values of Bosniak Category 1 and 3 cysts on DWIs at $b$ values of $800 \mathrm{~s} / \mathrm{mm}^{2}(\mathrm{p}<0.001)$ and $1600 \mathrm{~s} / \mathrm{mm}^{2}(\mathrm{p}<0.001)$. A cutoff value of $1.902 \times 10^{-3} \mathrm{~mm}^{2} / \mathrm{s}$ for the ADC with a b value of $800 \mathrm{~s} / \mathrm{mm}^{2}$ provided $88 \%$ sensitivity and $96 \%$ specificity for differentiation between benign and malignant renal lesions. A cutoff value of $1.623 \times 10^{-3}$ $\mathrm{mm}^{2} / \mathrm{s}$ for the ADC with a $\mathrm{b}$ value of $1600 \mathrm{~s} / \mathrm{mm}^{2}$ provided $79 \%$ sensitivity and $96 \%$ specificity $(p<0.001)$ for the differentiation between benign and malignant renal lesions.

Conclusion: Accurate assessment of renal masses is important for determining the necessity for surgical intervention. DWI provides additional value by differentiating benign from malignant renal tumors and can be added to routine kidney MRI protocols.

Keywords: Apparent diffusion coefficient, diffusionweighted magnetic resonance imaging, renal neoplasms, 3 T MRI
Magnetic resonance imaging (MRI) is an imaging modality that is becoming widely used for the evaluation of renal lesions. MRI has advantages including high contrast resolution, the ability to capture images in three planes, and a lack of ion- izing radiation in comparison to computed tomography (CT). The characterization of lesions can be performed more precisely by using MRI in comparison to ultrasound (US). Lesion morphologies, signal intensities, and enhancement patterns 
are evaluated during the MRI procedure. Despite all findings being assessed together, there may still be an overlap between benign and malignant lesions. Contrast-enhanced CT and MR are two of the most commonly used modalities for evaluation of renal masses (1). However, contrast agents increase costs and may have side effects.

The basic physical principle of diffusion-weighted imaging is based on the random movements of molecules (Brownian motion) in a spatial plane. This is affected by differences in the nucleocytoplasmic ratio and factors that change water diffusion in the interstitial space such as increased cell density and viscosity (2). The use of a contrast agent is not necessary for diffusion-weighted imaging (DWI). DWI can be performed in a single breath-hold. DWI was first used for the early diagnosis of stroke in neuroradiology. Initially, its use was limited to brain tissue due to its high sensitivity for cardiac, respiratory and peristaltic movements. However, it has recently begun to be used for abdominal examinations as a result of the development of fast MRI sequences such as echoplanar imaging (EPI) (3-5). DWI has been demonstrated to have advantages in the diagnosis of focal liver lesions and diffuse liver parenchymal diseases such as cirrhosis (6). Moreover, this technique can also be used for the evaluation of native and transplanted kidney lesions. There have been studies conducted on the differential diagnosis of hydronephrosis and pyonephrosis using DWI $(7,8)$.

The characterization of renal masses by imaging modalities such as US, CT and MRI would reduce the number of redundant invasive and surgical procedures. For this purpose, alternative imaging modalities like diffusion-weighted magnetic resonance imaging (DW-MRI) which does not involve contrast administration or ionizing radiation, has clinical importance.

Studies conducted on the assessment of renal lesions using DWI are rapidly increasing at present. Studies on $3 \mathrm{~T}$ MRI regarding the usage of DW-MRI in the differentiation between benign and malignant renal masses are limited in number. The efficacy of DW-MRI in the characterization of renal lesions was evaluated in the present study.

\section{MATERIALS AND METHODS}

This retrospective study was approved by the ethics committee of Dicle University, and all participants provided written informed consent.

We performed DWI on a total of 137 consecutive patients (74 female and 63 male) in whom a renal mass was diagnosed by ultrasonography (US), computed tomography (CT) or MRI in the period between February 2012 and June 2013.
We used the Bosniak classification to appoint cystic lesions prospectively. Type 1 lesions are thin walled simple cysts that contain fluid with the attenuation of water, without septae or calcification. Type 2 lesions are cystic lesions which may contain thin hairline septa. These cysts may have fine calcification in the walls (septae) or slightly thickened calcification in a short segment. The septum or cyst wall is minimally enhanced. Also, lesions which are less than $3 \mathrm{~cm}$ in diameter with uniformly high intensity on T1-weighted images but are not enhanced are included in type 2 . The first two types of the Bosniac classification are benign. Type III lesions are indeterminate cystic masses and suspected malignancy should be excluded. They have thick, irregular walls or septae, and may contain varied amounts of calcification. Cyst wall or septae are clearly enhanced. Type 4 lesions nearly always have a nonuniform or enhanced thick wall, large or enhanced nodules in the wall, or obviously solid components in the cystic lesion. These lesions are mostly clear and almost always malignant.

All images were obtained using a $3 \mathrm{~T}$ MR system (Intera Achieva, Philips Medical Systems, the Netherlands) equipped with a phased-array coil (six-channel). The breath hold DW images were obtained using a customized Black-Blood Spin EchoEcho Planar Imaging (BB SE-EPI) sequence. An XL TORSO coil was used with the channel numbers of 16 . In the coronal T2 TSE Breath Hold (BH) and coronal T2 TSE Free Breathing (FB), two b values (b 800 and b $1600 \mathrm{~s} / \mathrm{mm}^{2}$ ) using the transverse BB SE-EPI sequences were acquired. The scanning parameters were as follows: Coronal T2W TSE BH $(\mathrm{TR}=$ shortest, $\mathrm{TE}=80$, Slice Thickness $=6$, Interslice Gap $=1$, Matrix $=312 \times 247$, FOV $\mathrm{FH}=405$, NSA $=1$, Sense Factor $=\mathrm{P}$, Reduction $(\mathrm{RL})=2$, Voxel Size $=0.79$, Slice Number $=74$, Scan Time $=22-3$ ), Transverse T2W TSE FB $(\mathrm{TR}=$ shortest, $\mathrm{TE}=80$, Slice Thickness $=7$, Interslice Gap $=1$, Matrix $=284 \times 194$, FOV FH=255, NSA=1, Voxel Size $=0.73$, Slice Number $=32$, Scan Time $=1-36$, Transverse BB SE-EPI b 800 and b 1600 (Slice Thickness $=7$, Interslice $\mathrm{Gap}=1$, Matrix $=152 \times 112$, FOV FH=199, RL=450, AP=338, NSA=3, Sense Factor $=$ P, Reduction=2). The DWI acquisition was two minutes and 14 seconds in total. All of the MR images of the 137 patients were reviewed at the PACS workstation (Philips Workspace, Extended MR Workspace, release 2.6.3. 2009, Philips Medical Systems, The Netherlands). All of the images were analyzed by an abdominal radiologist with five years of experience. The segmental locations of all the lesions and the sizes of each lesion were electronically recorded. With the two $b$ values $\left(b=800 \mathrm{~s} / \mathrm{mm}^{2}\right.$ and $\left.b=1600 \mathrm{~s} / \mathrm{mm}^{2}\right)$, the quantitative ADC calculations were determined. The ADC values were calculated by inserting a region of interest (ROI) in three different locations of the masses. After calculating the mean ADC values, $\mathrm{ADC}$ values of renal tumors in two diffusion gradients were compared. ADC values of the contrast enhanced areas of solid tumors and entire lesion of cystic tumors were measured one 
by one. The smaller ROIs were placed on enhancing soft tissue areas of solid tumors. The necrotic area from the ROI analysis was excluded $\left(30 \mathrm{~mm}^{2}\right)$. The largest ROIs were placed on cystic renal tumors to evaluate the ADC values of whole lesions (150 $\mathrm{mm}^{2}$ ) manually.

Three ROI measurements were performed for each measurement, and the mean value of the measurements was accepted. ROIs that included motion artifacts were excluded. ADC in normal renal parenchyma was calculated from upper-lower renal pole and the central part of the corticomedullary junction.

Quantitative DWI findings were recorded for each patient, and they were compared with surgical and histopathological results. ADC values were compared between control group and patient groups.

\section{Statistical analysis}

Statistical analyses were performed by SPSS version 18.0 (SPSS Inc., Chicago, IL, USA). Data are presented as the mean and standard deviation or $\mathrm{n}(\%)$. The one-sample Kolmogorov-Smirnov test was used to evaluate the distribution of data. An unpaired Student's t-test was used to compare the mean ADC values between suspicious lesions and normal renal parenchyma after ensuring normal distribution by ShapiroWilk test. The Mann-Whitney U or Kruskal-Wallis tests were performed to compare the mean ADCs and histopathological variables. A $p$ value of less than 0.05 was considered to be a statistically significant difference. Receiver operating characteristic (ROC) analysis was done to evaluate the diagnostic performance of the ADC for differentiating benign and malign lesions. The significant cut-off value was determined to be the value that best discriminated between benign and malignant in terms of maximum sensitivity and specificity.

\section{RESULTS}

We enrolled 63 male and 74 female patients. The age of our study population ranged from 2 to 95 years, with a mean age of 55.54+16.59 years. In total, 137 patients with renal masses were included in this study. Forty-six of 137 patients underwent surgery; four of those 46 lesions were pyelonephritis, nine were hemorrhagic cysts, five were oncocytomas, and 28 were carcinomas (Figure 1). Of the remaining 91 patients who were not operated on based on imaging findings, 57 and 24 had Bosniak Category 1 and 2 cysts, respectively, and six had Bosniak Category 3 cysts. Bosniak Category 3 lesions were followed up. Four of the 91 lesions were angiomyolipomas.

The mean ADC value of normal renal parenchyma was 2.07 x $10^{-3}$ and $1.56 \times 10^{-3} \mathrm{~mm}^{2} / \mathrm{s}$ at b 800 and b $1600 \mathrm{~s} / \mathrm{mm}^{2}$, respectively. The mean ADC value of lesions that were totally included in the study was $2.28 \times 10^{-3}$ and $1.83 \times 10^{-3} \mathrm{~mm}^{2} / \mathrm{s}$ at b 800 and b $1600 \mathrm{~s} / \mathrm{mm}^{2}$, respectively. There were significant differences between the ADC value of lesions and normal renal parenchyma on DWI at b values of 800 and $1600 \mathrm{~s} / \mathrm{mm}^{2}$ $(\mathrm{p}<0.001$ and $\mathrm{p}<0.001$ respectively).

The mean ADC value of benign lesions was $2.52 \times 10^{-3}$ $\mathrm{mm}^{2} / \mathrm{s}\left(0.44-3.75 \times 10^{-3} \mathrm{~mm}^{2} / \mathrm{s}\right)$ and $2.03 \times 10^{-3} \mathrm{~mm}^{2} / \mathrm{s}(0.31-$ $\left.9.72 \times 10^{-3} \mathrm{~mm}^{2} / \mathrm{s}\right)$ at b 800 and b $1600 \mathrm{~s} / \mathrm{mm}^{2}$. The mean ADC value of malignant lesions was $1.29 \times 10^{-3} \mathrm{~mm}^{2} / \mathrm{s}(0.70-2.03$ x $\left.10^{-3} \mathrm{~mm}^{2} / \mathrm{s}\right)$ and $1.06 \times 10^{-3} \mathrm{~mm}^{2} / \mathrm{s}\left(0.62-1.74 \times 10^{-3} \mathrm{~mm}^{2} / \mathrm{s}\right)$ at b 800 and $\mathrm{b} 1600 \mathrm{~s} / \mathrm{mm}^{2}$. There were significant differences between the ADC values of benign and malignant lesions on DWIs at $b$ values of 800 and $1600 \mathrm{~s} / \mathrm{mm}^{2}(p<0.001$ and $\mathrm{p}<0.001$ respectively).

There were significant differences between the ADC values of Bosniak Category 1 and 2 cysts and the ADC values of Bos
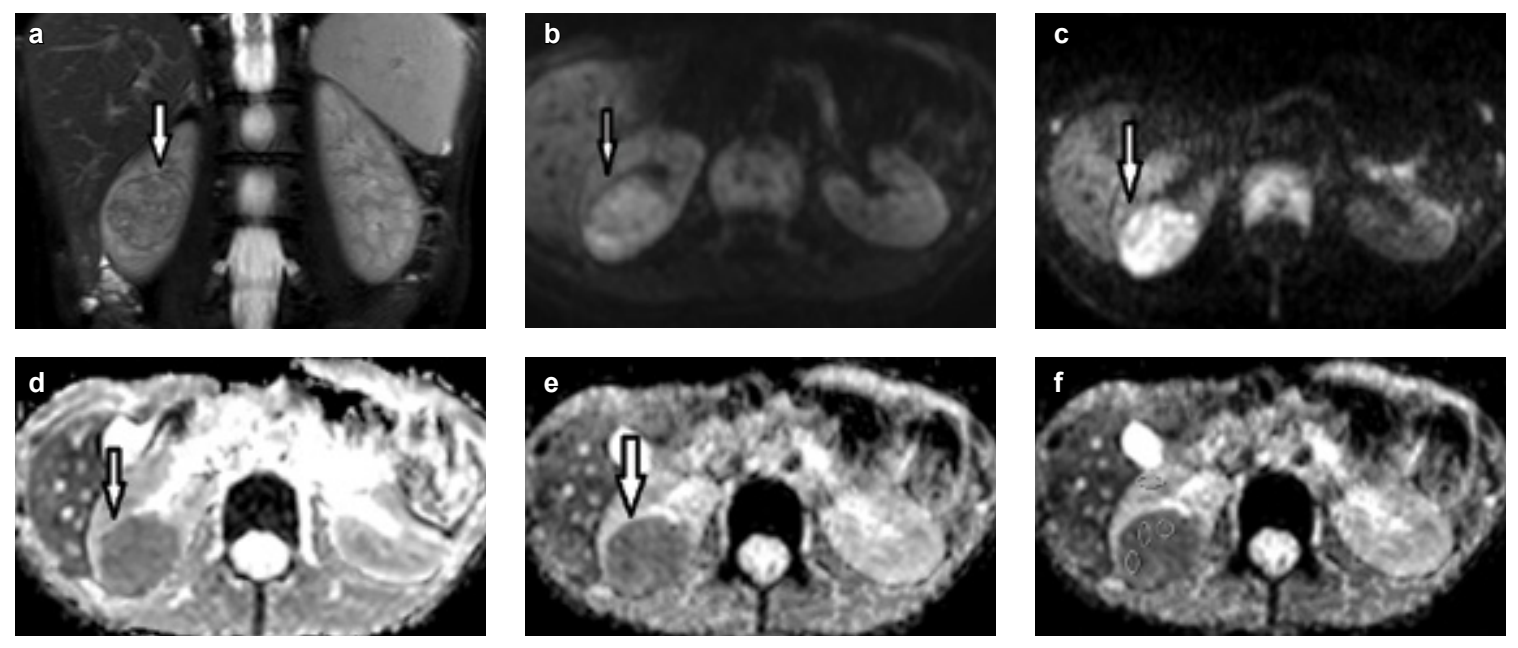

FIG. 1. a-f. A 25-year-old man with renal cell carcinoma in the right kidney. Fat-saturated T2-weighted image shows a hypointense mass in the right kidney. Signal intensity changes of the lesion were observed on DWls at different b values (800 and $\left.1600 \mathrm{~s} / \mathrm{mm}^{2}\right)(a-e)$ and auto ADC (f). The lesion showed high signal intensity compared with the normal renal parenchyma on DW images with two $b$ values. 
niak Category 1 and 3 cysts on DWIs at b values of $800 \mathrm{~s} / \mathrm{mm}^{2}$ $(p<0.001)$ and $(p<0.001)$, respectively. There were significant differences between the ADC values of Bosniak Category 1 and 2 cysts and the ADC values of Bosniak Category 1 and 3 on DWIs at $b$ values of $1600 \mathrm{~s} / \mathrm{mm}^{2}(\mathrm{p}=0.011$ and $\mathrm{p}=0.013$, respectively). There were significant differences between the ADC values of Bosniak Category 2 and 3 cysts on DWI at $b$ values of $800 \mathrm{~s} / \mathrm{mm}^{2}(\mathrm{p}<0.001)$. However, there was not a significant difference between the ADC value of Bosniak Category 2 and 3 cysts on DWI at $b$ values of $1600 \mathrm{~s} / \mathrm{mm}^{2}(p=0.21)$.

\section{ROC analysis and cut-off levels}

The cut off level for the ADC with $b$ values of $800 \mathrm{~s} / \mathrm{mm}^{2}$ derived from the ROC analysis was $1.902 \times 10^{-3} \mathrm{~mm}^{2} / \mathrm{s}(\mathrm{p}<0.001)$. The resulting sensitivity and specificity of DWI were $88 \%$ and $96 \%$, respectively. The cut off level for the ADC with $b$ values of $1600 \mathrm{~s} / \mathrm{mm}^{2}$ derived from the ROC analysis was $1.623 \times 10^{-3}$ $\mathrm{mm}^{2} / \mathrm{s}(\mathrm{p}<0.001)$. The resulting sensitivity and specificity of DWI were $79 \%$ and $96 \%$, respectively (Figure 2).

\section{DISCUSSION}

In this study, DW-MRI was performed for the characterization of renal lesions. ADC values of normal renal parenchyma and renal lesions differed significantly. The ADC values of benign lesions were significantly higher than the values of malignant lesions. When we classified renal cysts according to the Bosniak classification system, we observed that $\mathrm{ADC}$ values of Bosniak Category 1 cysts at b 800 and $1600 \mathrm{~s} / \mathrm{mm}^{2}$ were signifi- cantly higher than values of normal renal parenchyma. There was a significant difference between Bosniak Category 1 and 2 cysts and Bosniak Category 1 and 3 cysts in terms of ADC values at b $800 \mathrm{~s} / \mathrm{mm}^{2}$ and $1600 \mathrm{~s} / \mathrm{mm}^{2}$. There was a significant difference between Bosniak Category 2 and 3 cysts at b $800 \mathrm{~s} /$ $\mathrm{mm}^{2}$ but there was not a difference at b $1600 \mathrm{~s} / \mathrm{mm}^{2}$. A cutoff value of $1.90 \times 10^{-3} \mathrm{~mm}^{2} / \mathrm{s}$ for the $\mathrm{ADC}$ with $\mathrm{b}$ values of 800 $\mathrm{s} / \mathrm{mm}^{2}$ provided $88 \%$ sensitivity and $96 \%$ specificity. A cutoff value of $1.623 \times 10^{-3} \mathrm{~mm}^{2} / \mathrm{s}$ for the ADC with $\mathrm{b}$ values of 1600 $\mathrm{s} / \mathrm{mm}^{2}$ provided $79 \%$ sensitivity and $96 \%$ specificity $(\mathrm{p}<0.001)$.

Angiomyolipomas and oncocytomas are benign examples of solid renal masses. The most common malignant tumor of the kidney is renal cell carcinoma (RCC). Renal cell carcinomas are generally solid masses, but cystic forms of RCC may appear in $10-15 \%$ of patients. Benign cystic lesions are usually asymptomatic and are diagnosed incidentally. Renal cell cancer and loculated infections should be considered in the differential diagnosis. US, CT, MRI, or a combination of these techniques are used to determine whether a solid or cystic renal mass is benign or malignant $(9,10)$.

In a previous study, the ADC value for normal renal parenchyma was between $1.78-3.56 \times 10^{-3} \mathrm{~mm}^{2} / \mathrm{s}$ (11). We found a mean ADC value of $2.07 \times 10^{-3}$ and $1.56 \times 10^{-3} \mathrm{~mm}^{2} / \mathrm{s}$ at $\mathrm{b}$ values of 800 and b $1600 \mathrm{~s} / \mathrm{mm}^{2}$ in normal renal parenchyma, which is consistent with previously reported results. The ADC values of normal renal parenchyma and lesions using DWMRI at b0 and $500 \mathrm{~s} / \mathrm{mm}^{2}$ values have also been reported (8). It was found that the mean ADC value was $3.65 \times 10^{-3} \mathrm{~mm}^{2} / \mathrm{s}$ in simple cysts, and this value was significantly higher than normal renal parenchyma. In another study (12), it was demonstrated that the mean ADC value was $3.09 \times 10^{-3} \mathrm{~mm}^{2} / \mathrm{s}$ in
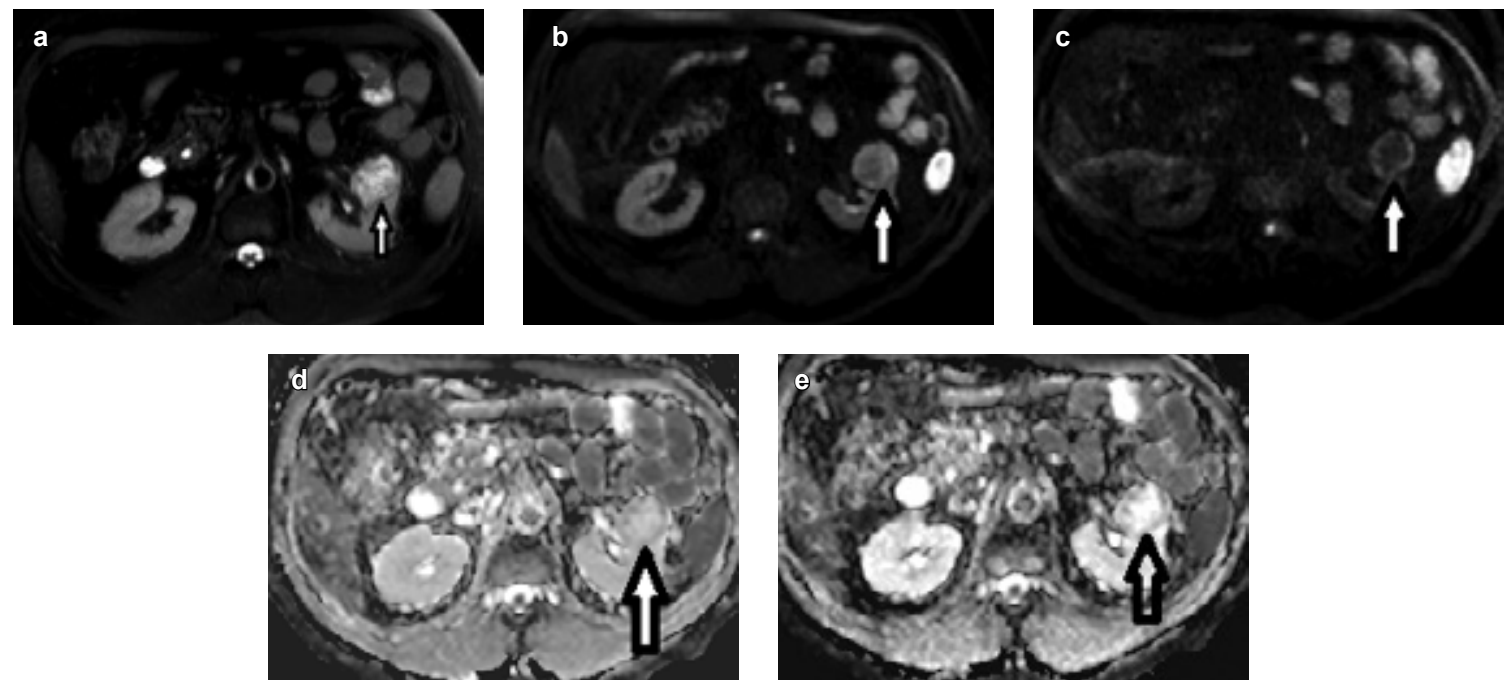

FIG. 2. a-e. A 60-year-old man with oncocytoma in the left kidney. Fat-saturated T2-weighted image shows a slightly hyperintense mass in the left kidney (a). Signal intensity changes of the lesion were observed on DWls at different b values (for b800 values: 2.05, and for b1600values: $1.57 \mathrm{~s} / \mathrm{mm} 2)(\mathrm{b}-\mathrm{c})$ and ADC (d-e). The lesion showed iso and slightly hyper signal intensity compared with the normal renal parenchyma on DW images with two $b$ values. 
simple renal cysts, which was higher than normal renal parenchyma. In our study, the mean ADC value of benign lesions was $2.52 \times 10^{-3} \mathrm{~mm}^{2} / \mathrm{s}\left(0.44-3.75 \times 10^{-3} \mathrm{~mm}^{2} / \mathrm{s}\right)$ and $2.03 \mathrm{x}$ $10^{-3} \mathrm{~mm}^{2} / \mathrm{s}\left(0.31-9.72 \times 10^{-3} \mathrm{~mm}^{2} / \mathrm{s}\right)$ at b 800 and $\mathrm{b} 1600 \mathrm{~s} /$ $\mathrm{mm}^{2}$, respectively. Consistent with the other studies, the ADC values of benign lesions were higher than the values of normal renal parenchyma.

In two different studies, Inci et al. (12) conducted a study on RCC and found that the ADC value was $1.11 \times 10^{-3} \mathrm{~mm}^{2} / \mathrm{s}$ and $1.38 \times 10^{-3} \mathrm{~mm}^{2} / \mathrm{s}$ at $\mathrm{b}$ values of 500 and $10001000 \mathrm{~s} / \mathrm{mm}^{2}$, respectively. In both studies, the ADC values of malignant lesions were lower than the values of normal renal parenchyma. In another study, Manenti et al. (13) reported statistically significant differences among the ADC values of carcinomas and normal parenchyma. In our study, the mean ADC values of malignant lesions were $1.29 \times 10^{-3} \mathrm{~mm}^{2} / \mathrm{s}\left(0.70-2.031 \times 10^{-3} \mathrm{~mm}^{2} / \mathrm{s}\right)$ and $1.06 \times 10^{-3} \mathrm{~mm}^{2} / \mathrm{s}\left(0.62-1.74 \times 10^{-3} \mathrm{~mm}^{2} / \mathrm{s}\right)$ at b 800 and $\mathrm{b} 1600$ $\mathrm{s} / \mathrm{mm}^{2}$, which are significantly lower than those of normal renal parenchyma $(\mathrm{p}<0.001)$, similar to previous studies.

It has been shown that the mean ADC value of solid tumors is $1.55 \times 10^{-3} \mathrm{~mm}^{2} / \mathrm{s}(8)$, which was lower than the value of simple cysts $\left(3.65 \times 10^{-3} \mathrm{~mm}^{2} / \mathrm{s}\right)$. In another study (14), it was observed that the ADC value of solid renal tumors $(2.49 \mathrm{x}$ $\left.10^{-3} \mathrm{~mm}^{2} / \mathrm{s}\right)$ was lower than the value of simple cysts $(3.82$ $\mathrm{x} 10^{-3} \mathrm{~mm}^{2} / \mathrm{s}$ ) as well. Moreover, DW-MRI with quantitative ADC measurements (15) may be useful in the differentiation between benign and malignant renal lesions. High $b$ values (600 and $1000 \mathrm{~s} / \mathrm{mm}^{2}$ ) had the best specificity and sensitivity when AML (angiomyolipoma) was excluded. In our study, the mean ADC values of benign lesions were $2.52 \times 10^{-3} \mathrm{~mm}^{2} / \mathrm{s}$

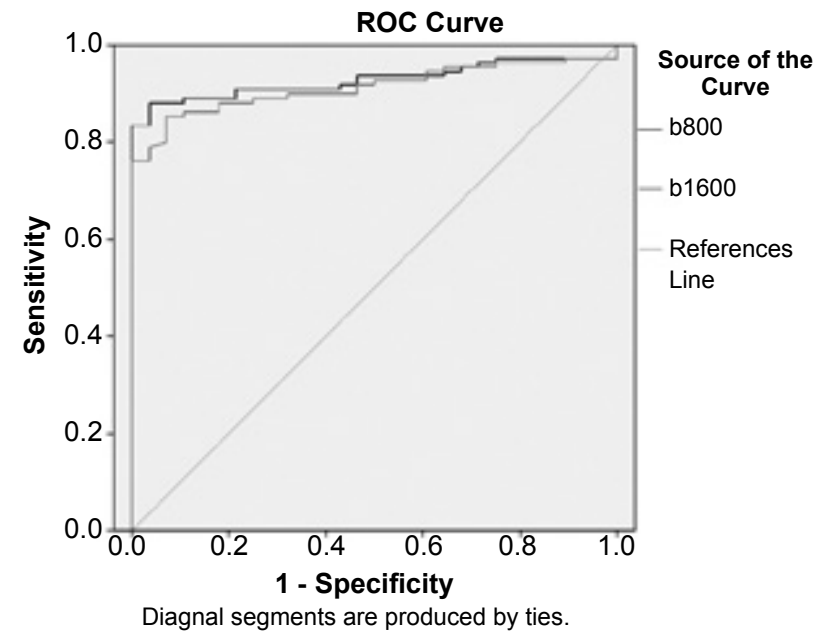

FIG. 3. Graph shows receiver operating characteristic curve for apparent diffusion coefficient (ADC) values. Area under curve, which represents probability that lesion will be classified accurately as benign or malignant according to ADC with b values of $800 \mathrm{~s} / \mathrm{mm}^{2}$ is 0.92 , and $A D C$ with $b$ values of $1600 \mathrm{~s} / \mathrm{mm}^{2}$ is 0.91 . Upper left point on curve is the cutoff value of ADC with the highest sensitivity and specificity. $\left(0.44-3.75 \times 10^{-3} \mathrm{~mm}^{2} / \mathrm{s}\right)$ and $2.03 \times 10^{-3} \mathrm{~mm}^{2} / \mathrm{s}(0.31-9.72$ x $10^{-3} \mathrm{~mm}^{2} / \mathrm{s}$ ) at b 800 and b $1600 \mathrm{~s} / \mathrm{mm}^{2}$, respectively. The mean ADC values of malign lesions were $1.29 \times 10^{-3} \mathrm{~mm}^{2} / \mathrm{s}$ $\left(0.70-2.03 \times 10^{-3} \mathrm{~mm}^{2} / \mathrm{s}\right)$ and $1.06 \times 10^{-3} \mathrm{~mm}^{2} / \mathrm{s}(0.62-1.74 \mathrm{x}$ $10^{-3} \mathrm{~mm}^{2} / \mathrm{s}$ ) at b 800 and b $1600 \mathrm{~s} / \mathrm{mm}^{2}$. There were significant differences between the ADC values of benign and malignant lesions on DWI at $b$ values of 800 and $1600 \mathrm{~s} / \mathrm{mm}^{2}(p<0.001$ and $p<0.001$ respectively). In a meta-analysis study, Lassel et al. (16) observed that the evaluation of ADC values can help to distinguish between benign and malignant lesions, and it also seems able to differentiate oncocytomas from malignant tumors, hence potentially reducing the number of unnecessarily performed nephrectomies.

The simple renal cysts had the highest ADCs because of their fluid content, with unrestricted motion of water molecules. In a previous study, Inci et al. (12) reported a mean $\mathrm{ADC}$ value of $3.09 \pm 0.14 \times 10^{-3} \mathrm{~mm}^{2} / \mathrm{s}$ in Bosniak Category I cysts. The mean ADC value in Bosniak Category I cysts $(n=20)$ was remarkably higher than that of normal renal parenchyma $(p<0.01)$. A statistically significant difference was determined between the signal intensities of Bosniak Category I and Category II-III cysts at $\mathrm{b} 1000(\mathrm{p}<0.05)$. We found a mean $\mathrm{ADC}$ value of $2.93 \pm 0.14 \times 10^{-3} \mathrm{~mm}^{2} / \mathrm{s}$ in Bosniak Category I cysts, which was higher than the value of normal renal parenchyma, $2.49 \pm 0.30 \times 10^{-3} \mathrm{~mm}^{2} / \mathrm{s}$ in Bosniak Category II cysts, and $1.95 \pm 0.27 \times 10^{-3} \mathrm{~mm}^{2} / \mathrm{s}$ in Bosniak Category III cysts. There was a significant difference between Bosniak Category I and III cysts and Bosniak Category I and II cysts in terms of ADC values using DW-MRI at a b value of $800(p<0.001$ and $\mathrm{p}<0.001)$. A significant difference was observed between Bosniak Category I and II cysts and Bosniak Category I and III cysts in terms of ADC values using DWI at a b value of 1600 $(p=0.011$ and $p=0.013)$. ADC values of Bosniak Category II and III cysts at $b$ value of 800 differed significantly $(p<0.001)$. Additionally, there was a significant difference between the ADC values of Bosniak Category II and III cysts at $b$ value of 1600 with a higher $p$ value $(p=0.021)$ than at $b$ value of 800 ; hereby, the usage of higher $b$ values might be considered as impractical when compared with the $b$ value of 800 . Further studies should be performed to clarify the issue.

Focal renal lesion characterization and staging/grading of cancer prediction are the advantages of DWI. On the other hand, contrast-enhanced imaging and pathology are required as additional data for DWI. ADC can be falsely decreased in renal abscesses and elevated in cystic RCCs. This limitation of DWI decreases the sensitivity and specificity of ADC measurements for the diagnosis of neoplasms (17).

In a previous study, significant differences were shown between the ADC values of the subtypes of malignant tumors, while there were no significant differences between benign and malignant lesions in terms of the ADC values. The explanation 
for this conclusion can be the exclusion of the cystic lesions from the relevant study and the discrepancy in the number and variety of the lesions when compared with our study (18).

The limitations of our study were as follows. Our patient population of the subgroups was small. The second limitation is that not all of the lesions were diagnosed histopathologically, and only common types of focal renal lesions were studied. Finally, using a higher $b$ value of single-shot echo-planar imaging had a lower SNR, and this condition led to image distortions.

In conclusion, MRI is a useful modality as an investigative tool for diagnosing, characterizing, and staging renal masses. DWI contributes additional value by allowing the differentiation of benign from malignant renal tumors and can be added to routine kidney MRI protocols. The acquisition of DWI and $\mathrm{ADC}$ values can be used to reduce unnecessary surgery in these patients. It is possible to place these patients into "active surveillance" by serial MR imaging with ADC as a routine component. Additionally, measuring signal intensities of trace diffusion images and ADC values may also be useful in subgrouping renal cysts.

Ethics Committee Approval: Ethics committee approval was received for this study from the ethics committee of Dicle University.

Informed Consent: Written informed consent was obtained from patients who participated in this study.

Peer-review: Externally peer-reviewed.

Author contributions: Concept - C.G., H.G., Y.B.; Design C.G., H.G., Y.B.; Supervision - S.K., A.B., G.T.; Resource - A.Y., S.H.,C.H.; Materials - C.G., C.H., A.Y.; Data Collection \&/or Processing - C.G., H.G., A.B.; Analysis \&/or Interpretation - G.T., S.H.; Literature Search - A.Y., C.H.; Writing - C.G., A.Y., H.G.; Critical Reviews - C.G., C.H., Y.B., A.Y., S.K., H.G., G.T., S.H., A.B.

Conflict of Interest: No conflict of interest was declared by the authors.

Financial Disclosure: The authors declared that this study has received no financial support.

\section{REFERENCES}

1. Zhang J, Tehrani YM, Wang L, Ishill NM, Schwartz LH, Hricak H. Renal masses: characterization with diffusion-weighted MR imaging-a preliminary experience. Radiology 2008;247: 458-64. [CrossRef]

2. Le Bihan D, Turner R, Douek P, Patronas N. Diffusion MR imaging: clinical applications. AJR Am J Roentgenol 1992;159:591-9. [CrossRef]

3. Warach S, Chien D, Li W, Ronthal M, Edelman RR. Fast magnetic resonance diffusion-weighted imaging of acute human stroke. Neurology 1992;42:1717-23. [CrossRef]
4. Back T, Hoehn-Berlage M, Kohno K, Hossmann KA. Diffusion nuclear magnetic resonance imaging in experimental stroke. Correlation with cerebral metabolites. Stroke 1994;25: 494-500. [CrossRef]

5. Lutsep HL, Albers GW, DeCrespigny A, Kamat GN, Marks MP, Moseley ME. Clinical utility of diffusion-weighted magnetic resonance imaging in the assessment of ischemic stroke Ann Neurol 1997;41:574-80. [CrossRef]

6. Kim T, Murakami T, Takahashi S, Hori M, Tsuda K, Nakamura H. Diffusion-weighted single-shot echoplanar MR imaging for liver disease. AJR Am J Roentgenol 1999;173:393-8. [CrossRef]

7. Ichikawa T, Haradome H, Hachiya J, Nitatori T, Araki T. Diffusion-weighted MR imaging with single-shot echo-planar imaging in the upper abdomen: preliminary clinical experience in 61 patients. Abdom Imaging 1999;24:456-61. [CrossRef]

8. Cova M, Squillaci E, Stacul F, Manenti G, Gava S, Simonetti G, et al. Diffusion-weighted MRI in the evaluation of renal lesions: preliminary results. Br J Radiol 2004;77:851-7. [CrossRef]

9. Semelka RC, Hricak H, Stevens SK, Finegold R, Tomei E, Carroll PR. Combined gadolinium-enhanced and fat-saturation MR imaging of renal masses. Radiology 1991;178:803-9. [CrossRef]

10. Ho VB, Allen SF, Hood MN, Choyke PL. Renal masses: quantitative assessment of enhancement with dynamic MR imaging. Radiology 2002;224:695-700. [CrossRef]

11. Yu X, Lin M, Ouyang H, Zhou C, Zhang H. Application of ADC measurement in characterization of renal cell carcinomas with different pathological types and grades by $3.0 \mathrm{~T}$ diffusionweighted MRI. Eur J Radiol 2012;81:3061-6. [CrossRef]

12. Inci E, Hocaoglu E, Aydin S, Cimilli T. Diffusion-weighted magnetic resonance imaging in evaluation of primary solid and cystic renal masses using the Bosniak classification. Eur J Radiol 2012;81:815-20. [CrossRef]

13. Manenti G, Di Roma M, Mancino S, Bartolucci DA, Palmieri $\mathrm{G}$, Mastrangeli R, et al. Malignant renal neoplasms: correlation between ADC values and cellularity in diffusion weighted magnetic resonance imaging at 3 T. Radiol Med 2008;113:199-213. [CrossRef]

14. Yoshikawa T, Kawamitsu H, Mitchell DG, Ohno Y, Ku Y, Seo Y, et al. ADC measurement of abdominal organs and lesions using parallel imaging technique. AJR Am J Roentgenol 2006;187:1521-30. [CrossRef]

15. Doganay S, Kocakoc E, Cicekci M, Aglamis S, Akpolat N, Orhan I. Ability and utility of diffusion-weighted MRI with different $b$ values in the evaluation of benign and malignant renal lesions. Clin Radiol 2011;66:420-5. [CrossRef]

16. Lassel EA, Rao R, Schwenke C, Schoenberg SO, Michaely HJ. Diffusion-weighted imaging of focal renal lesions: a meta-analysis. Eur Radiol 2014;24:241-9. [CrossRef]

17. Kim S, Jain M, Harris AB, Lee VS, Babb JS, Sigmund EE, et al. T1 hyperintense renal lesions: characterization with diffusionweighted MR imaging versus contrast-enhanced MR imaging. Radiology 2009;251:796-807. [CrossRef]

18. Sevcenco S, Heinz-Peer G, Ponhold L, Javor D, Kuehhas FE, Klingler HC, et al. Utility and limitations of 3-Tesla diffusionweighted magnetic resonance imaging for differentiation of renal tumors. Eur J Radiol 2014;83:909-13. [CrossRef] 